\title{
Topical Treatment for Orbital Capillary Hemangioma in an Adult Using a $\beta$-Blocker Solution
}

\author{
Ken Ohnishi ${ }^{\mathrm{a}}$ Mizuki Tagami $^{\mathrm{a}} \quad$ Eiichi Morii $^{\mathrm{b}}$ Atsushi Azumia \\ ${ }^{a}$ Ophthalmology Department, Kobe Kaisei Hospital, Kobe, and ${ }^{b}$ Department of Pathology, \\ Osaka University Graduate School of Medicine, Suita (Japan)
}

\section{Key Words}

Orbital capillary hemangioma $\cdot$ Topical treatment $\cdot$ Timolol maleate $\cdot$ Adult case

\begin{abstract}
Purpose: To report a case of orbital capillary hemangioma in an adult who was successfully treated with topical timolol maleate $0.5 \%$ solution. Methods: Case report. Results: A 43 -yearold female presented both superficial and deep orbital capillary hemangioma. Topical timolol maleate was applied twice daily. The superficial lesions have nearly disappeared after 1 year of treatment. The deeper lesions have also been reduced in size according to MRI. Conclusion: We report an adult patient with a relatively large orbital capillary hemangioma who was successfully treated with a topical $\beta$-blocker solution. This treatment might be applicable for orbital capillary hemangiomas, regardless of the patient's age, because of its effectiveness and safety.

(c) 2014 S. Karger AG, Basel
\end{abstract}

\section{Introduction}

Capillary hemangioma is a common benign vascular tumor of childhood. Within the ocular region, it normally begins on the eyelid but can occasionally occur in the orbit [1]. Histologically, it is characterized by proliferating endothelial cells. It generally appears within a few weeks after birth and undergoes a rapid proliferating phase, followed by a period of quiescence, regressing after a few years into an involution phase [2].

Rootman [3] classified these lesions based on the level of involvement (superficial, subcutaneous, deep orbital, or combined). Capillary hemangiomas of the eyelid and orbit have also been categorized according to their size. Schwartz et al. [4] reported that half of the cases involving hemangiomas with a widest diameter of $\geq 1 \mathrm{~cm}$ would require treatment. 
Possible acceptable indications for medical intervention include rapidly enlarging lesions, obstruction of the visual axis, significant induced astigmatism and cosmetic concerns. The modalities currently available include intralesional and systemic steroids, bleomycin, interferon- $\alpha$, topical timolol maleate, oral propranolol, laser treatment and surgical excision [5-10].

We report the case of capillary hemangioma in an adult, which is rare, who was successfully treated with topical timolol maleate $0.5 \%$ solution. To our knowledge, this is the first reported application of timolol maleate for an orbital capillary hemangioma in an adult.

\section{Case Report}

A 43-year-old female was admitted to hospital with a complaint of bleeding from the right medial ocular angle. She had had a long history of capillary hemangiomas, as described below.

She had developed capillary hemangiomas of the right upper eyelid at the age of 4 and of the right buccal region at the age of 9 . Both of those lesions were surgically excised the time of development. She had also developed a right orbital tumor at the age of 13, which was monitored without any treatment. She presented at the age of 34 with a complaint of right proptosis with ocular pain due to the right orbital tumor, which was confirmed to be an orbital capillary hemangioma after being pathologically diagnosed from an endoscopic biopsy at that time. In the biopsy sample, a lot of dilated capillaries were observed in the mucosa (fig. 1a, arrows), indicating that the lesion was a capillary hemangio$\mathrm{ma} /$ malformation, but not infantile hemangioma. Radiation therapy and surgical excision were considered but rejected due to a risk of visual loss since the lesion was too close to the optic nerve. Fortunately, the right proptosis with ocular pain had almost disappeared 2 months later with no treatment other than the biopsy. She was then observed without any treatment for years.

Her best-corrected visual acuity was $1.2 \mathrm{OD}$ and $1.5 \mathrm{OS}$, and the intraocular pressure was $12 \mathrm{~mm} \mathrm{Hg}$ in both eyes. Slit-lamp examination revealed no abnormalities except the superficial lesions of the capillary hemangioma of her right eye. No abnormalities were found in the retinas of either eye.

The hemangioma presented both superficial and deep orbital components. The superficial lesion was seen at the right medial ocular angle, that is, on the upper/lower eyelids, conjunctiva and expanding into the subconjunctival space. It appeared as superficial tortuous blood vessels, and the conjunctiva appeared violet/blue in color (fig. 1b-d). The deeper lesion lay posterior to the orbital septum and was detected using MRI with low signal intensity on T1-weighted images versus high signal intensity on T2-weighted images with internal signal void (fig. 2a, arrows) and gadolinium enhancement.

The patient was instructed to apply an ophthalmic solution of timolol maleate $0.5 \%$ twice daily. The superficial lesion gradually regressed, as shown in fig. 3a-c, and had almost disappeared after 1 year of treatment (fig. 3d). The deeper lesion had also reduced in size, with maximal MRI axial dimensions of $16 \times 11 \mathrm{~mm}$ (fig. 2a), decreasing to $12 \times 8 \mathrm{~mm}$ (fig. $2 \mathrm{~b}$, arrow) after 1 year of treatment. No apparent recurrence of bleeding in her eye was observed. No local or systemic adverse effects were noted. 
Ohnishi et al.: Topical Treatment for Orbital Capillary Hemangioma in an Adult Using a $\beta$-Blocker Solution

\section{Discussion}

In recent years, propranolol has yielded encouraging results for capillary hemangioma and is becoming a standard treatment [7]. However, systemic propranolol therapy in children has been associated with a significant incidence of adverse effects such as bronchospasm, bradycardia, hypotension and hypoglycemia [11]. The markedly low rate of adverse reactions to topical timolol maleate treatment reported thus far suggests that it is a safer alternative to systemic propranolol $[10,12]$.

Our case demonstrated that topical timolol maleate can be delivered effectively to the superficial lesions of capillary hemangiomas in adult patients. It is also effective for the deeper components of capillary hemangiomas to some extent. A further interesting point is that $\beta$-blockers are effective not only during the early phase in infants but also in the mature structure of capillary hemangiomas in adults.

Little is known regarding the working mechanism of non-selective $\beta$-blockers in the treatment of capillary hemangiomas. Capillary hemangiomas consist of a complex mixture of various types of cells [13]. Immature endothelial cells coexist with immature pericytes, and angiogenic peptides, such as basic fibroblast growth factor and vascular endothelial growth factor, induce proliferation of these immature cells, eventually developing into capillary hemangiomas [13]. $\beta$-blockers could potentially influence the signal transduction pathway of these angiogenic factors by modulating the $\beta$-adrenergic receptor system, which would explain their effect during the proliferative phase [14]. Other studies demonstrate that nonspecific $\beta$-blockers are able to trigger apoptosis in capillary endothelial cells in adult rat lung tissue [15]. A similar mechanism might be applicable to the endothelial cells of hemangiomas. Our case suggests that $\beta$-blockers can treat capillary hemangiomas even after the completion of tumor growth.

In conclusion, we report the rare case of an adult patient with a relatively large orbital capillary hemangioma who was treated successfully with topical timolol. Topical $\beta$-blocker solutions might be applicable to orbital capillary hemangiomas, regardless of the patient's age, because of their effectiveness and safety. Several unresolved issues remain such as the appropriate duration of treatment and the risk of recurrence. A further follow-up of the patient and research on other adults treated with topical timolol for capillary hemangiomas are necessary.

\section{References}

1 Shields JA: Vasculogenic tumors and malformations. Capillary hemangioma; in Shields JA (ed): Diagnosis and Management of Orbital Tumors. Philadelphia, WB Saunders, 1989, pp 124-128.

-2 Haik B, Karcioglu Z, Gordon RA, Pechous BP: Capillary hemangioma (infantile periocular hemangioma). Surv Ophthalmol 1994;38:399-426.

3 Rootman J: Diseases of the Orbit. Philadelphia, JB Lippincott, 1988, pp 539-543.

4 Schwartz SR, Blei F, Ceisler E, et al: Risk factors for amblyopia in children with periocular capillary hemangiomas of the eyelid and orbit. J AAPOS 2006;10:262-268.

5 Wasserman BN, Medow NB, Homa-Palladino M, Hoehn ME: Treatment of periocular capillary hemangiomas. J AAPOS 2004;8:175-181.

6 Weiss AH, Kelly JP: Reappraisal of astigmatism induced by periocular capillary hemangioma and treatment with intralesional corticosteroid injection. Ophthalmology 2008;115:390-397.

-7 Haider KM, Plager DA, Neely DE, et al: Outpatient treatment of periocular infantile hemangiomas with propranolol. J AAPOS 2010;14:251-256.

-8 Leaute-Labreze C, Dumas de la Roque E, Hubiche T, et al: Propranolol for severe hemangiomas of infancy. N Engl J Med 2008;358:2649-2654.

-9 Elsas FJ, Lewis AR: Topical treatment of periocular capillary hemangioma. J Pediatr Ophthalmol Strabismus 1994;31:153-156. 


\begin{tabular}{l|l}
\hline Case Rep Ophthalmol 2014;5:60-65 & \\
\hline DOI: $10.1159 / 000360392$ & $\begin{array}{l}\text { @ 2014 S. Karger AG, Basel } \\
\text { www.karger.com/cop }\end{array}$ \\
\hline
\end{tabular}

Ohnishi et al.: Topical Treatment for Orbital Capillary Hemangioma in an Adult Using a ß-Blocker Solution

10 Guo S, Ni N: Topical treatment for capillary hemangioma of the eyelid using beta-blocker solution. Arch Ophthalmol 2010;128:255-256.

11 Siegfried EC, Keenan WJ, Al-Jureidini S: More on propranolol for hemangiomas of infancy. N Engl J Med 2008;359:2846-2847.

12 Xue K, Hildebrand G: Deep periocular infantile capillary hemangiomas responding to topical application of timolol maleate, 0.5\% drops. JAMA Ophthalmol 2013;131:1246-1248.

$\$ 13$ Takahashi K, Mulliken JB, Kozakewich HP, et al: Cellular markers that distinguish the phases of hemangioma during infancy and childhood. J Clin Invest 1994;93:2357-2364.

14 Iaccarino G, Ciccarelli M, Sorriento D, et al: Ischemic neoangiogenesis enhanced by beta2-adrenergic receptor overexpression: a novel role for the endothelial adrenergic system. Circ Res 2005;97:1182-1189.

15 Sommers Smith SK, Smith DM: Beta blockade induces apoptosis in cultured capillary endothelial cells. In Vitro Cell Dev Biol Anim 2002;38:298-304.
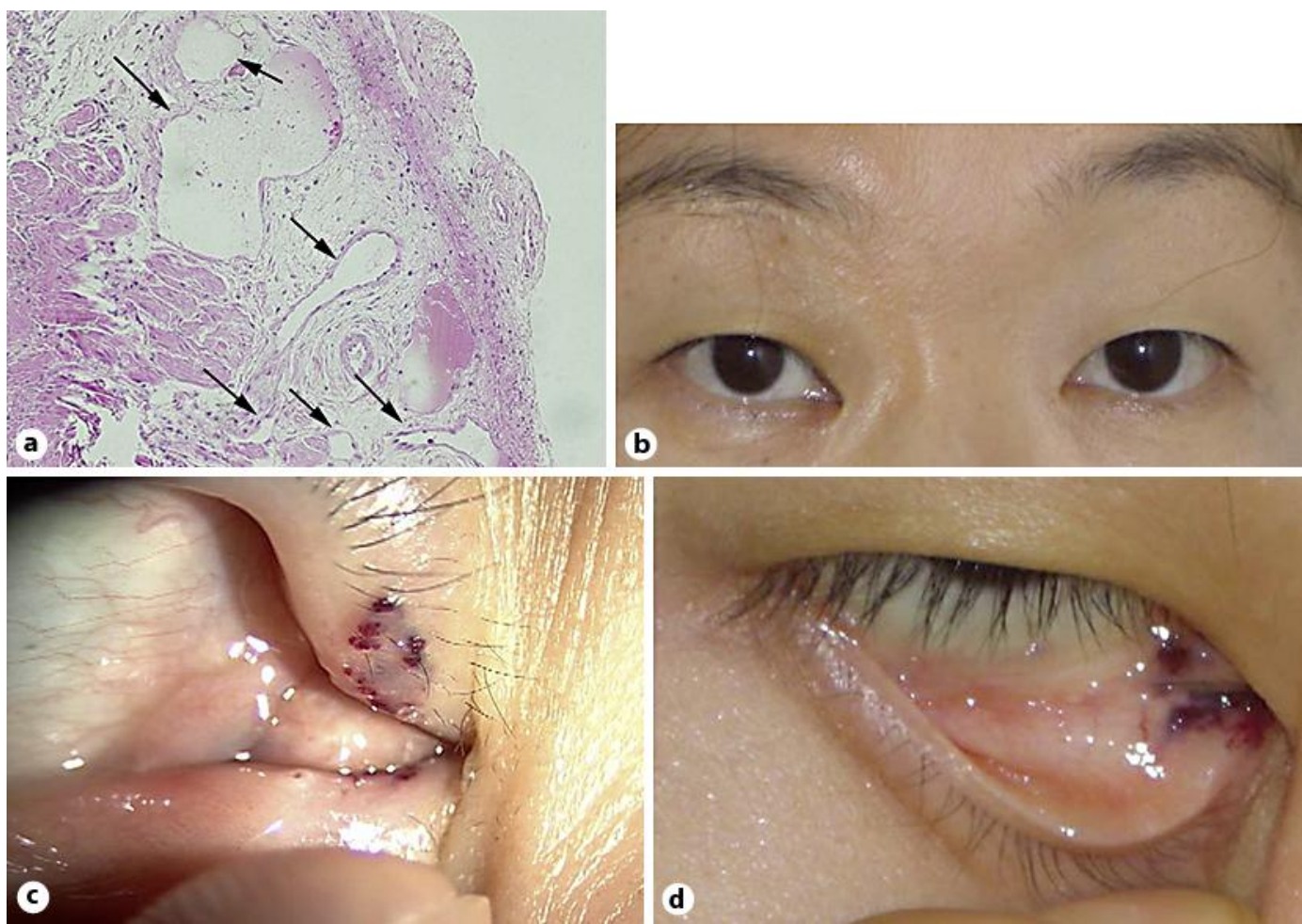

Fig. 1. a Histology of the biopsy sample. A lot of dilated capillaries were observed in the mucosa (arrows). $\times 100$. b Facial appearance: almost no external lesions on the right eyelid. No proptosis can be seen. $\mathbf{c}$, d Close-up view of the superficial lesion at the right medial ocular angle. Superficial tortuous blood vessels are visible. 
Case Reports in

Ophthalmology
Case Rep Ophthalmol 2014;5:60-65

DOI: $10.1159 / 000360392$

Ohnishi et al. Topical Treatment for Orbital Capillary Hemangioma in an Adult Using a $\beta$-Blocker Solution
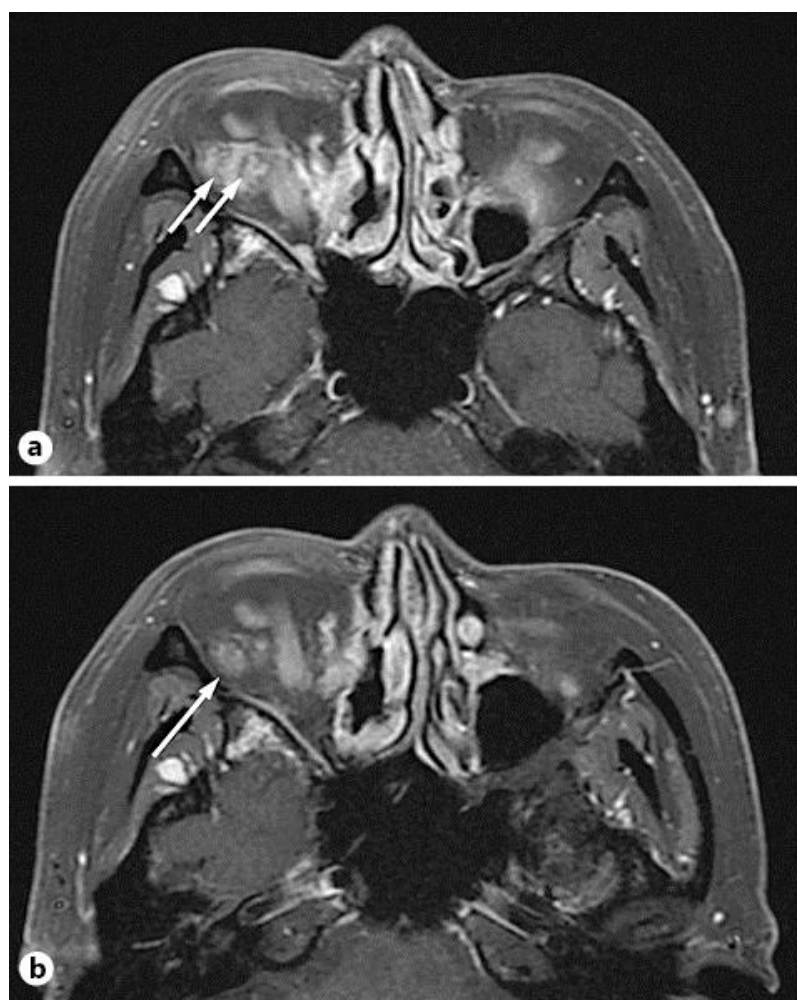

Fig. 2. a Gadolinium-enhanced MRI before treatment, with maximal dimensions of $16 \times 11 \mathrm{~mm}$. Internal signal voids (arrows) represent internal high-flow vessels. b After 1 year of topical timolol treatment, a reduction in size $(12 \times 8 \mathrm{~mm}$, arrow $)$ can be seen. 
Ohnishi et al: Topical Treatment for Orbital Capillary Hemangioma in an Adult Using a $\beta$-Blocker Solution
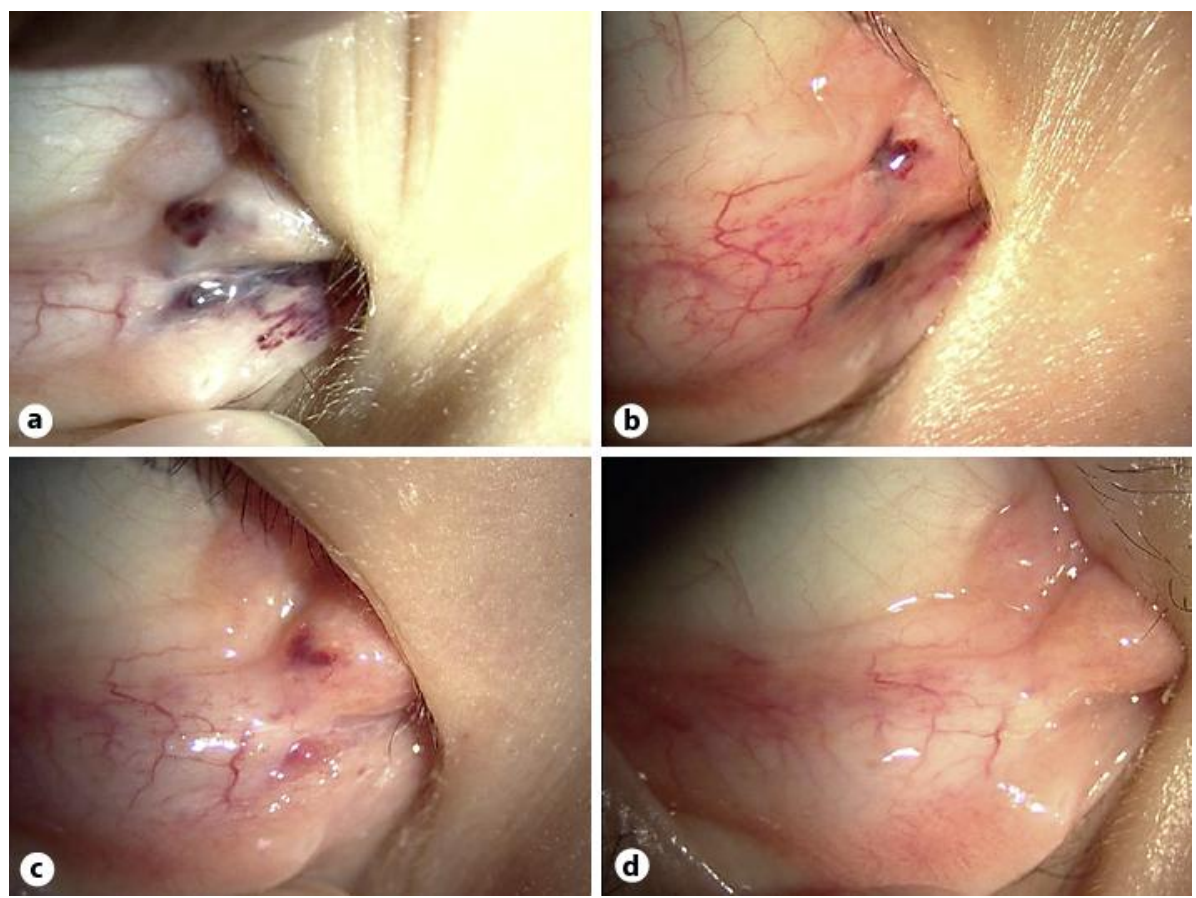

Fig. 3. Close-up view of the superficial lesions. a Photo at initial presentation. The lesions can be seen in the eyelids, conjunctiva and expanding into the subconjunctival space. b Four months later, the lesions were partially reduced. c Eight months later, a clear tendency toward regression can be seen. $\mathbf{d}$ After 1 year of treatment, the lesions were nearly absent. 